\title{
STUDY THE EFFECT OF URBAN ECOSYSTEM TO FLOATING POPULATION
}

\author{
Wubin Tu ${ }^{1,2}$, Lingxian Zhang ${ }^{2}$, Xiaoshuan Zhang ${ }^{2}$, Zetian $\mathrm{Fu}^{2, *}$ \\ ${ }^{1}$ College of Engineering China Agricultural university, Beijing P.R China 100083 \\ ${ }^{2}$ Key laboratory for modern precision agriculture integration Ministry of Education, China \\ Agricultural University, Beijing P.R/China 100083 \\ * Corresponding author, Address: Key laboratory for modern precision agriculture \\ integration Ministry of Education. Address: Key laboratory for modern precision \\ agricultural integration Ministry of Education, China Agricultural University, 17 Tsinghua \\ East Road, Beijing 100083, P.R.China. Tel: +86-10-62737617, Fax: +86-10-62737617, \\ Email:tomy_twb@sina.com
}

\begin{abstract}
The urban ecosystem is a complex system hat are compounded of environment -economic-social ,the factors of urban ecosystem affect the decision of the floating population to chose city .In this paper, we according to the urban ecosystem to design the questionnaire, and study the weights of the factors that influence the decision by AHP , and find that economy is most important which is 0.6806 , the society and ecological environment are 0.2014 and 0.1180 .
\end{abstract}

Keywords: urban ecosystem, floating population, AHP

\section{INTRODUCTION}

The economic reform in China that started in 1978 has Created a "floating population" Which is one of the most mobile population in the word (Zhigang LU et al ,2006; Yu Zhu,2007), a huge floating population of ruralurban migrants is transforming the urban force (Michael C.Seeborg et al 2000). There are over 14,735 million floating population according to data of the 2005 China 1\% Population Sample Survey, of which the interprovince floating population is 47.79 million. Because China has been experiencing a great transition from planned to market economy, and the transition has been accompanied by the increasing mobility of production

Please use the following format when citing this chapter:

Tu, W., Zhang, L., Zhang, X. and Fu, Z., 2009, in IFIP International Federation for Information Processing, Volume 295, Computer and Computing Technologies in Agriculture II, Volume 3, eds. D. Li, Z. Chunjiang, (Boston: Springer), pp. 1881-1888. 
factors such as: capital, labor ,technology and information (Chaolin Gu et al, 2006). On one hand so huge floating population meet the demand for labor of the rapid economic development of cities, on the other hand they lower the level of the structure of the working population and they become the importing factors that constraint the upgrading of the industrial structure to some extent, meanwhile as so many population move to cities, it glowed the density of urban population and caused many environmental and social issues (Peter Nannestad,2007; Pia M. Orrenius et al ,2007) .There are many elements that pulled so great number population moving to cities in China: higher income in cities, better opportunities ,better education ,better quality of life in cities and others ( Zhigang Lu et al ,2006;Sandra Poncet ,2006) besides the characteristics of the population themselves ,such as education level, sex and age(Tracy Simmons,2007) .

The studies on floating population mainly focused on the management of them, the staying time of floating population(Wang guanzhou, et al 2002;Zhu Haiyan,2001), and the influence that the floating population to economic of city( Zhou Chang lin et al ,2007). There are many cities in China, what's the determinants of the city that attract man to move to ? In this paper,we according to the urban ecosystem theory and analytic hierarchy process(AHP) to study the characteristics of city that attract men to move to.

\section{URBAN ECOSYSTEM}

The urban ecosystem is a complex system that are compounded of environment -economic-social, characterized by high level, multiple hierarchy and dynamical structure(Forrester JW. 1967,) environmental economic - social compounds, cities evolve along the life cycle of growth, maturity and stagnation, and behave according to the inner changing mix of the factors involved under the support and constraint of the social and biophysical environment (Button K. 2002) It is shown in Fig. 1. As the center of the system, human is the main activities of social production and life, and floating population is an important component of the subject. 


\section{MODEL OF FLOATING POPULATION CHOSE CITY}

\subsection{Analytic Hierarchy Process (AHP)}

The AHP is an efficient approach to make multi-objective decision that employs pair wise comparison to determine the weights and priorities of a variety of factors, attributes, elements and alternatives. Because Urban ecosystem is a multiple hierarchy, there are many factors ,so we applied AHP to study the degree which affect the moving to city .

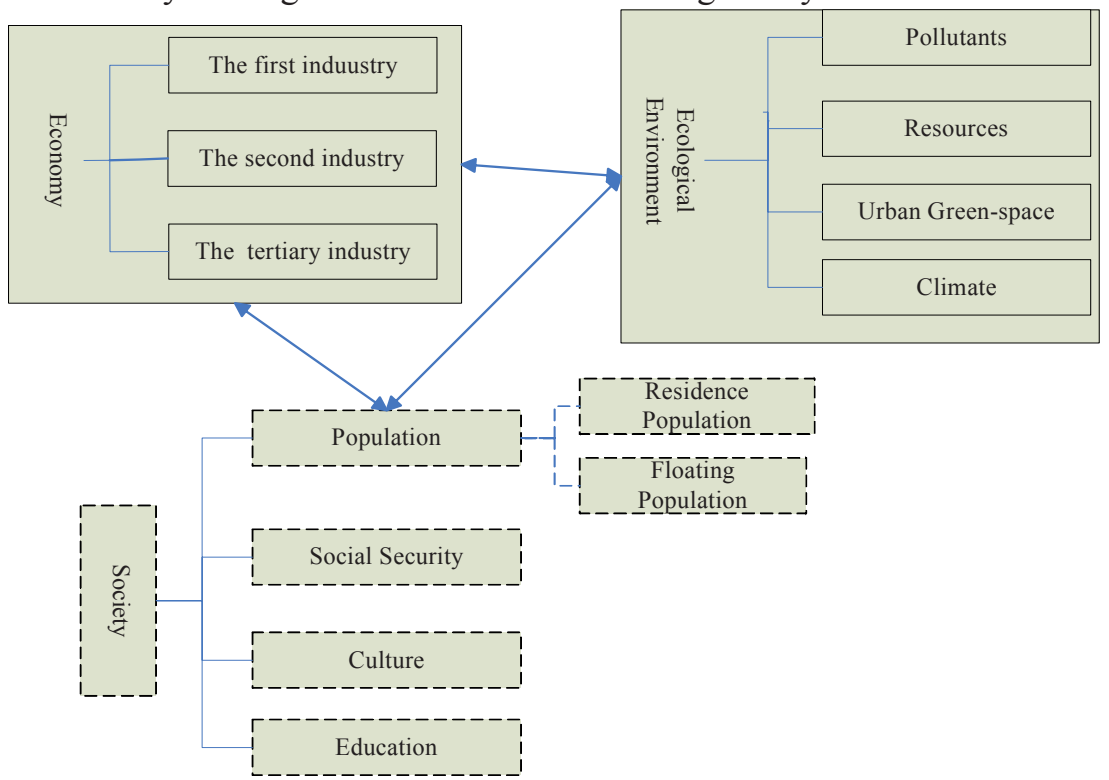

Fig 1. The framework of urban ecosystem

\subsection{Hierarchy structural model}

To study the determinants of floating population to choose city ,we according urban ecosystem, which is a multiple hierarchy system ,so we adopted AHP to get weights of each factors that influence the decision. The structure of AHP is shown in Fig.2.

(1) A-Objective layer: Choose city .First , the floating population should decide what kind of cities they want to .then we could calculate orderly the power and weight of different factors effect on the general objective in order to know the reason why they chose the city .

(2) C-Criterions layer: This layer includes : society, economy and ecological environment which are the three main compositions. To weigh 
and distinguish the estimating standard effecting on the object layer, the criterions layer can be divided into several sub-layers according to the the urban ecosystem theory .

(3) P-Policy alternatives layer: This layer includes 11 factors, they are expressed with expressed with $\mathrm{Pi}, \mathrm{i}=1,2, \ldots, 11$ respectively. They are the subsystem of society ,economy and ecological environment .

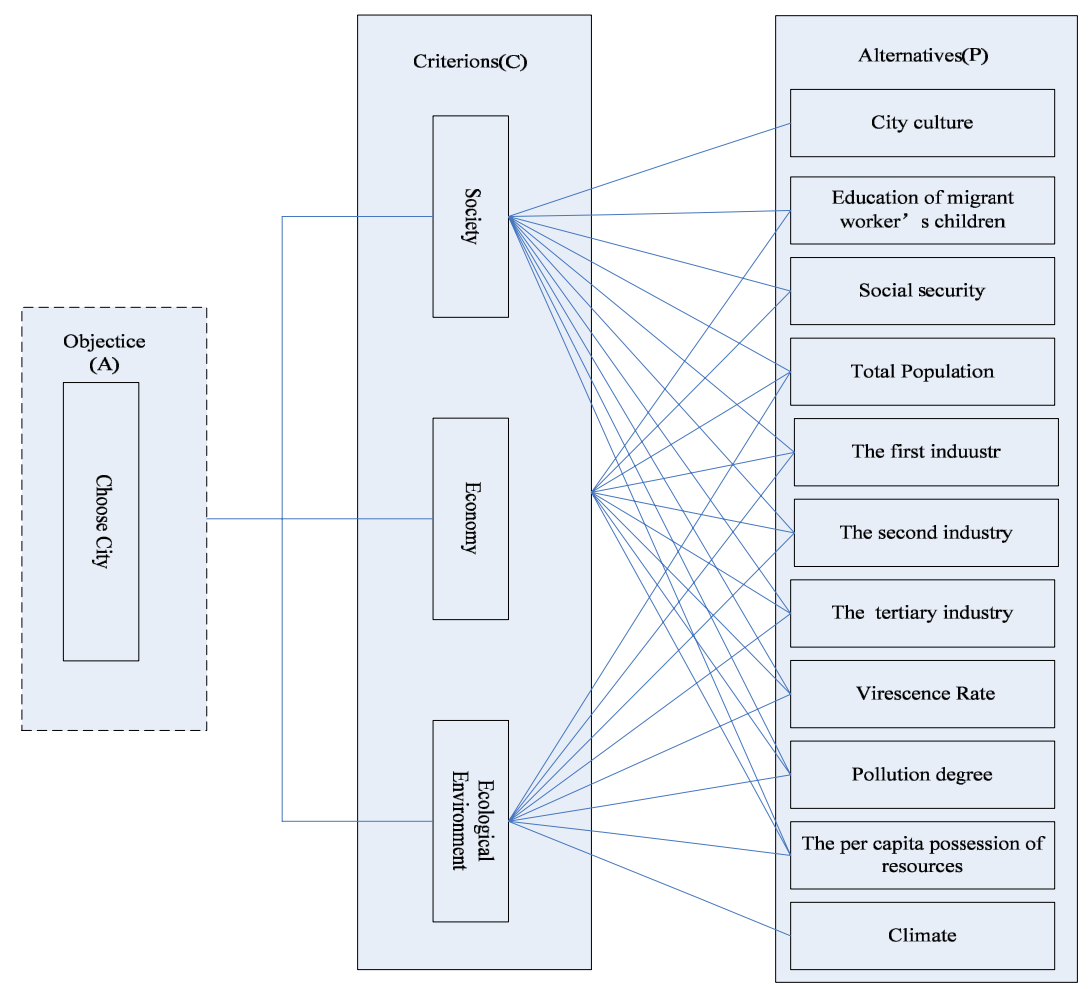

Fig 2. The hierarchy structural model for determinants of floating population chose city

\subsection{Assessing policy preferences: analytic hierarchy process}

The comparison matrix provides a measure of the weight factor for the decision making, which denotes the relative importance of the element of each layer shown in the hierarchical structural model. Often from top to bottom, the comparison matrix could be established with one elements of above layer pair wise comparing with all the elements of the neighboring below layer according to the relations between the elements or the layers.

Between layer A and C showed in Fig.2, the comparison matrix of A-C layer can be established as Table 1, which elements are evaluated using 9- 
point scale shown in Table 2. The pairwise comparison of element $\mathrm{i}$ with element $\mathrm{j}$ of $\mathrm{C}$ layer is placed in the position of $c_{i j}$ of the comparison matrix of A-C layer as shown in Table 1.

The comparison matrix is a square matrix as $\mathrm{A}=\left(\mathrm{c}_{\mathrm{ij}}\right)_{\mathrm{n} \times \mathrm{n}}$, and:

$$
\mathrm{c}_{\mathrm{ij}}>0 ; \quad \mathrm{c}_{\mathrm{ij}}=1 / \mathrm{c}_{\mathrm{ji}} ; \quad \mathrm{c}_{\mathrm{ii}}=\mathrm{c}_{\mathrm{jj}}=1
$$

Similarly, the comparison matrix of C-P layers can be obtained in term of the method of forming the comparison matrix of A-C layers. Data on pairwise comparison matrices were collected from reviewers. Score of $c_{i j}$ were estimated by doing survey in seven provinces in china : Beijing ,Shanghai, Guangzhou , Jiangsu ,Sichuan ,Jiangxi and Hebei then according to the survey, We choose 300 Valid questionnaires. The participants are all with the local "hukou", it includes : farmers and college students from rural areas we took full account of gender, marital status, academic qualifications and the proportion in the survey .

Table1 The comparison matrix of A-C layer

\begin{tabular}{ccccc}
\hline $\mathrm{A}$ & $\mathrm{C}_{1}$ & $\mathrm{C}_{2}$ & $\mathrm{C}_{3}$ & $\mathrm{C}_{4}$ \\
$\mathrm{C}_{1}$ & $\mathrm{C}_{11}$ & $\mathrm{C}_{12}$ & $\mathrm{C}_{13}$ & $\mathrm{C}_{14}$ \\
$\mathrm{C}_{2}$ & $\mathrm{C}_{21}$ & $\mathrm{C}_{22}$ & $\mathrm{C}_{23}$ & $\mathrm{C}_{24}$ \\
$\mathrm{C}_{3}$ & $\mathrm{C}_{31}$ & $\mathrm{C}_{32}$ & $\mathrm{C}_{33}$ & $\mathrm{C}_{34}$ \\
$\mathrm{C}_{4}$ & $\mathrm{C}_{41}$ & $\mathrm{C}_{42}$ & $\mathrm{C}_{43}$ & $\mathrm{C}_{44}$ \\
\hline
\end{tabular}

\section{EVALUATION PROCESS AND RESULTS}

\subsection{Single ranks of the A-C hierarchical level}

We explained the table to the participants then the filled the table according their own judgment about the importance of these factors The results are in Table 3.

Consistency test : $\lambda_{\max }=4.0325, \quad \mathrm{CI}=(4.0325-4) / 3=0.01083, \quad \mathrm{RI}=0.89$

$$
\mathrm{CR}=\mathrm{CI} / \mathrm{RI}=0.01083 / 0.89=0.01216<0.1 \quad \text { (accepted })
$$

Similarly we get the C-P level ranking and $C R$ results of which are $0.0583,0.0623$ and 0.0303 respectively. They are wholly less than 0.1 . It shows that several matrices are very consistent and pass the consistency test (accepted). 
Table. 2 The 9-point scale for pair wise comparisons

\begin{tabular}{cll}
\hline Score & \multicolumn{1}{c}{ Description } & \multicolumn{1}{c}{ Comprehension } \\
\hline 3 & Equal influence & $\begin{array}{l}\text { Two elements contribute equally to the } \\
\text { objective }\end{array}$ \\
\cline { 2 - 3 } 5 & $\begin{array}{l}\text { Moderate influence of one } \\
\text { over another }\end{array}$ & $\begin{array}{l}\text { Experience and judgment slightly favours } \\
\text { one element over another }\end{array}$ \\
\cline { 2 - 3 } 7 & Essential or strong influence & $\begin{array}{l}\text { Experience and judgment strongly favours } \\
\text { one element over another }\end{array}$ \\
\cline { 2 - 3 } 2 & Obvious importance & $\begin{array}{l}\text { An element is favored very strongly over } \\
\text { another, its dominance is demonstrated in } \\
\text { practice }\end{array}$ \\
\cline { 2 - 3 } $2,4,6$, and 8 & $\begin{array}{l}\text { The evidence favouring one element over } \\
\text { another is affirmed to the highest possible } \\
\text { order }\end{array}$ \\
\cline { 2 - 3 } & $\begin{array}{l}\text { Intermediate values between } \\
\text { adjacent values }\end{array}$ & $\begin{array}{l}\text { Further subdivision or compromise is } \\
\text { needed }\end{array}$ \\
\hline
\end{tabular}

Table 3.Comparison matrix of A-C layer

$\begin{array}{lcccc}A & C_{1} & C_{2} & C_{3} & \text { weight } \\ C_{1} & 1.000 & 0.2500 & 2.000 & 0.2014 \\ C_{2} & 4.000 & 1.000 & 5.000 & 0.6806 \\ C_{3} & 0.500 & 0.2000 & 1.000 & 0.1180\end{array}$

\subsection{Overall rank of the hierarchical level}

Overall rank of the hierarchical level is the importance rank of the elements of $\mathrm{P}$ to the general objective of $\mathrm{A}$. The calculated method is shown as Table 4. The over rank of the hierarchical level is show in Table 5.

Table 4. Calculated method for overall ranks of the hierarchical level

\begin{tabular}{cccccc}
\hline & $C_{1}$ & $C_{2}$ & $C_{3}$ & $C_{4}$ & Overall rank of the hierarchical level \\
\cline { 2 - 6 } & $W_{C_{1}}$ & $W_{C_{2}}$ & $W_{C_{3}}$ & $W_{C_{4}}$ & $\sum_{\mathrm{i}=1}^{4} \mathrm{~W}_{\mathrm{C}_{\mathrm{i}}} \mathrm{W}_{\mathrm{P}_{\mathrm{j}}^{\mathrm{i}}}(\mathrm{j}=1,2, \ldots, \mathrm{n})$ \\
\hline$P_{1}$ & $W_{P_{1}^{l}}$ & $W_{P_{1}^{2}}$ & $W_{P_{1}^{3}}$ & $W_{P_{1}^{4}}$ & $\sum_{i=1}^{4} W_{C_{i}} W_{P_{l}^{i}}$ \\
$P_{2}$ & $W_{P_{2}^{l}}$ & $W_{P_{2}^{2}}$ & $W_{P_{2}^{3}}$ & $W_{P_{2}^{4}}$ & $\sum_{i=1}^{4} W_{C_{i}} W_{P_{2}^{i}}$ \\
$P_{3}$ & $W_{P_{3}^{l}}$ & $W_{P_{3}^{2}}$ & $W_{P_{3}^{3}}$ & $W_{P_{3}^{4}}$ & $\sum_{\mathrm{i}=1}^{4} \mathrm{~W}_{\mathrm{C}_{\mathrm{i}}} \mathrm{W}_{\mathrm{P}_{3}^{\mathrm{i}}}$ \\
$P_{4}$ & $W_{P_{4}^{l}}$ & $W_{P_{4}^{2}}$ & $W_{P_{4}^{3}}$ & $W_{P_{4}^{4}}$ & $\sum_{i=1}^{4} W_{C_{i}} W_{P_{4}^{i}}$ \\
$\vdots$ & $\vdots$ & $\vdots$ & $\vdots$ & $\vdots$ & $\sum_{\mathrm{i}=1}^{4} \mathrm{~W}_{\mathrm{C}_{\mathrm{i}}} \mathrm{W}_{\mathrm{P}_{\mathrm{n}}^{\mathrm{i}}}$ \\
$\mathrm{P}_{\mathrm{n}}$ & $\mathrm{W}_{\mathrm{P}_{\mathrm{n}}^{1}}$ & $\mathrm{~W}_{\mathrm{P}_{\mathrm{n}}^{2}}$ & $\mathrm{~W}_{\mathrm{P}_{\mathrm{n}}^{3}}$ & $\mathrm{~W}_{\mathrm{P}_{\mathrm{n}}^{4}}$ & 1.00 \\
$\sum$ & 1.00 & 1.00 & 1.00 & 1.00 &
\end{tabular}

Notes: In the hierarchy structural model, $\mathrm{n}$ represented 11 
Table 5. The infection weight of different urban factors that affects the decision of floating population $(C R=\mathrm{CI} / \mathrm{RI})$

\begin{tabular}{ccccc}
\hline \multirow{2}{*}{$\mathrm{P}$} & $\mathrm{C}_{1}$ & $\mathrm{C}_{2}$ & $\mathrm{C} 3$ & \multirow{2}{*}{ Integrated weights } \\
\cline { 2 - 4 } & 0.2014 & 0.6806 & 0.1180 & \\
\hline $\mathrm{P}_{1}$ & 0.0679 & 0 & 0 & 0.0137 \\
$\mathrm{P}_{2}$ & 0.1476 & 0.0913 & 0 & 0.0913 \\
$\mathrm{P}_{3}$ & 0.1214 & 0.1192 & 0 & 0.1153 \\
$\mathrm{P}_{4}$ & 0.0769 & 0.0806 & 0.0709 & 0.0867 \\
$\mathrm{P}_{5}$ & 0.0351 & 0.0462 & 0.0562 & 0.0462 \\
$\mathrm{P}_{6}$ & 0.2007 & 0.2057 & 0.1465 & 0.1979 \\
$\mathrm{P}_{7}$ & 0.2097 & 0.2237 & 0.1422 & 0.2163 \\
$\mathrm{P}_{8}$ & 0.0463 & 0.0758 & 0.1601 & 0.0713 \\
$\mathrm{P}_{9}$ & 0.0535 & 0.0964 & 0.1893 & 0.0820 \\
$\mathrm{P}_{10}$ & 0.0409 & 0.0610 & 0.1183 & 0.0664 \\
$\mathrm{P}_{11}$ & 0 & 0 & 0.1159 & 0.0129 \\
$\mathrm{CI}$ & 0.095 & 0.0532 & 0.0407 & 0.0818 \\
$\mathrm{RI}$ & 1.4840 & 1.4040 & 1.3410 & 1.4125 \\
\hline
\end{tabular}

\subsection{Analysis}

From table3. the weights are: $0.2014,0.6806,0.1180$ respectively, so in the opinion of floating population that economy is much more important than the others .according Zhigang $\mathrm{Lu}$ ( 2006) rural people migrate to city to seek higher income ,better opportunities, a better quality of life and a better education for themselves and their children .The most important is higher income and better opportunities in city, they are all related to economy . The income gap between urban and rural areas is increasing, it is more than 2.5 now., and there are many Surplus labor in rural areas, so many people in rural areas move into city to earn money, but more of than are in the second and tertiary industry, so they put them at top . From the table 5, the weight of social security(P3) is 0.1153 , is the third important of all, because China's unique household registration (Hukou) system, the floating population can not share the same rights and benefits of urban Hukou residents, so most of the floating population hope that they can share the security of health, unemployment and old-age insurance Excepted the three, there are another 8 factors that also effect the decision, they are culture, education for children, total population, the first industry, Virescence Rate pollution degree, the per capita possession of resources and climate, and the weights of them are: $0.0137,0.0913,0.0867,0.0462,0.0713,0.0820,00664,0.0129,0.0818$ respectively.

\section{CONCLUSION}

The urban ecosystem effects the decision of the floating population's chose of city, the economy is the most important factor they consider, 
because in city they can get higher income ,but the society and ecological environment also have influence in the decision, the main factors are culture, education for children, social security ,total population ,the first industry, the second industry ,the tertiary, virescence Rate, pollution degree, the per capita possession of resources and climate, and their weights are : 0.0.137, $0.0913,0.1153,0.0867,0.0462,0.1946,0.2163,0.0713,0.0820,00664$, $0.0129,0.0818$ respectively.

\section{ACKNOWLEDGMENTS}

We acknowledge financial support from the National Science \& Technology Support Program (2006BAD10A07-02), National 863 Program (2006AA10Z267) from Ministry of Science \& Technology of China, and Beijing Municipal Science \& Technology Commission (ZZ0521) for financial support.

\section{REFERENCE}

Button K. City management and urban environmental indicators. Ecol Econ 2002;40:217 - 33.

Chaolin Gu, Roger C,K.Chan ,Jinyuan Liu ,Christaian Kesteloot .(2006).Beijing's sociospatial restructuring: Immigration and social transformation in the epoch of national economic reformation ,Progress in Planning 66,249-310.

Forrester JW. Urban dynamics. Cambridge: MIT Press; 1967.

Michael C. Seeborg, Zhenhu Jin, Yiping Zhu. (2000) The new rural-urban labor mobility in China: Causes and implications, The Journal of Socio-Economics, 29, 39-56.

Peter Nanestad .(2007). Immigration and welfare states :A survey of 15 years of research ,European Journal of Political Economy,23,512-532.

Pia M.Orrenius mMadeline Zavodny .(2007). Dose immigration affacr wages? A look at occupation-lebel evidence, Labor Economics, 14,757-773.

Sandra Poncet.(2006) Procincical migration dynamics in China : Borders ,costs and economic motibations ,Regional Science and Urban Economics 36,385-398.

Simmons, T., Sexuality and immigration: UK family reunion policy and the regulationof sexual citizens in the European Union, Political Geography (2007), doi:10.1016/j.polgeo. 2007.10.002.

Wang Guangzhou ,Tong Yu fen ,Lu Jie hua ,(2002) . Staying time of floating population in Beijing and its impact strength,Population \&Economic, 119,51-54(in Chinese)

$\mathrm{Yu}$ Zhu.(2007) .China's floating population and their settlement intention in the cities :Beyond the Hukou reform ,Habit International,31, 65-76.

Zhigang Lu ,Shunfeng Song. (2006). Rural-urban migration and wage determination: The case of Tianjin ,China, China Economic Review ,17,337-345.

Zhu Haiyan .(2001). A study on factors affecting the staying time of in -floating population in beijng,Market and Demographic analysis, 1,58-64.(in Chinese) 